\title{
Applications of Kinetic Methods in Thermal Analysis: A Review
}

\author{
Xin Zhang
}

\begin{abstract}
Determining kinetic parameters such as activation energy $\left(E_{a}\right)$, pre-exponential factor $(A)$, rate constant $(r)$, and reaction order $(n)$ via thermal analysis techniques is important to material synthesis and fabrication, industrial production, biomedicals, energy storage, catalysis, etc. Various kinetic methods based on non-isothermal techniques have been developed to obtain kinetic parameters. In this review, we aim to summarize various kinetic methods for non-isothermal analysis and their applications in different reactions, including thermal decomposition, solid-state phase transformation, crystallization, thermal ignition, curing process, etc.
\end{abstract}

Keywords: Kinetic Methods; Thermal Analysis; Non-isothermal; Activation Energy.

Received date: 21 June 2020; Accepted date: 4 September 2020.

Article type: Review article.

\section{Introduction}

Determining kinetic parameters such as activation energy $\left(\mathrm{E}_{\mathrm{a}}\right)$, pre-exponential factor $(\mathrm{A})$, rate constant (r), and reaction order (n) via thermal analysis techniques is important to material synthesis and fabrication, industrial production, biomedicals, energy storage, catalysis, etc. ${ }^{[1-6]}$ The isothermal technique was developed for kinetic studies first. For example, as early as in 1905, G. N. Lewis has explored the decomposition of $\mathrm{Ag}_{2} \mathrm{O}$ using the isothermal method. ${ }^{[7]}$ The non-isothermal method was developed for the kinetic analysis in 1930s. ${ }^{[8]}$ The experimental techniques involve Thermogravimetric analysis (TGA), Differential scanning calorimetry (DSC), Differential thermal analysis (DTA), Derivative Thermogravimetry (DTG), Evolved gas analysis (EGA), etc. An overview of the history about the isothermal and non-isothermal kinetic analysis methods could be obtained from Vyazokin's review paper. $^{8}$ Compared with the isothermal technique, the non-isothermal kinetic analysis method has several advantages. Firstly, the isothermal technique needs some time to reach the required experimental temperature. During the pre-heating process, the sample may experience some changes that could influence the kinetic analysis. This problem is particularity obvious when using a high temperature in isothermal experiments. The nonisothermal method solves this problem very well. Second, for the multiple decomposition reactions, the isothermal

Physical and Computational Science Directorate, Pacific Northwest National Laboratory, Richland, Washington 99354, United State.

*E-mail: Xin.Zhang@pnnl.gov (X. Zhang) technique cannot detect all reactions in a short time when using a low heating temperature and will lose important information for the low temperature reactions when using a high heating temperature. However, the non-isothermal method could observe all changes efficient. Several papers have reviewed the development of non-isothermal method, ${ }^{[8,9]}$ the applicability of the kinetic methods in thermal analysis, ${ }^{[10,}$ 11] and the applications of non-isothermal methods in specifically fields such as the pyrolysis of woody biomass ${ }^{[12]}$ and microalgae, ${ }^{[13]}$ and crystallization of glass-forming liquids. ${ }^{[14]}$ In this review, we aim to summarize various kinetic methods for non-isothermal analysis and their applications in different reactions, including thermal decomposition, solidstate phase transformation, crystallization, curing, thermal ignition, etc.

\section{Kinetic Methods}

In the last several decades, various non-isothermal kinetic methods, which depend on relationships between heating rates and temperatures that the reaction reaches a maximum value, have been developed to obtain kinetic parameters. The most well- known approaches are Kissinger ${ }^{[15]}$ and Ozawa ${ }^{[16]}$ methods.

\subsection{Kissinger and Kissinger-Akahira-Sunose Methods}

The Kissinger method was developed by Homer E. Kissinger in 1957. ${ }^{[15]}$ Because of the method is rapid and easy-to-use, it has been become one of the most popular approaches for determining kinetic parameters via thermal analysis. To today, May 31, 2020, the first paper ${ }^{[15]}$ that reported the Kissinger 
model has been cited by more than 5600 literatures (5605 citations in Web of Science, 9757 citations in Scopus, and 12505 citations in Google Scholar).

The Kissinger method relays on a series of experiments that heating samples at several (always three or four) different heating rates by using thermal analysis instruments such as DSC and DTA. Then the reaction exothermic peak temperature at each heating rate are recorded to calculate the kinetic parameters. For a thermal reaction, the rate of conversion can be described by two separate functions $f(x)$ and $k(T):{ }^{[17-19]}$

$$
\frac{d x}{d t}=f(x) k(T)
$$

where $x$ is the conversion; $f(x)$ is the function of the conversion; $t$ is the time; $k(T)$ is the rate constant; and $T$ is the Kelvin temperature.

Based on Arrhenius equation:

$$
k(T)=A \exp \left(-\frac{E_{a}}{R T}\right)
$$

where $A$ is the pre-exponential factor for the thermal reaction, $R$ is the gas constant, and $E_{a}$ is the activation energy.

The rate of conversion can be written as: ${ }^{[17-19]}$

$$
\frac{d x}{d t}=f(x) \operatorname{Aexp}\left(-\frac{E_{a}}{R T}\right)
$$

For the function of the conversion:

$$
f(x)=(1-x)^{n}
$$

where $n$ is the empirical order of the reaction.

Then the rate of the conversion can be described as: ${ }^{[17-19]}$

$$
\frac{d x}{d t}=A(1-x)^{n} \exp \left(-\frac{E_{a}}{R T}\right)
$$

Taking the derivative from both sides: ${ }^{[15]}$

$$
\begin{aligned}
\frac{d}{d t}\left(\frac{d x}{d t}\right)=A(1- & x)^{n} \frac{d\left[\exp \left(-\frac{E_{a}}{R T}\right)\right]}{d t} \\
& +A \exp \left(-\frac{E_{a}}{R T}\right) \frac{d\left[(1-x)^{n}\right]}{d t}
\end{aligned}
$$

When a sample is heated at a constant rate $\beta$, the temperature changes linearly:

$$
T=T_{0}+\beta t
$$

Taking the derivative from both sides:

$$
\frac{d T}{d t}=\beta
$$

Then the equation 6 can be written as:

$$
\begin{gathered}
\frac{d}{d t}\left(\frac{d x}{d t}\right)=A(1-x)^{n} \exp \left(-\frac{E_{a}}{R T}\right) \frac{\beta E_{a}}{R T^{2}} \\
-A \exp \left(-\frac{E_{a}}{R T}\right) n(1-x)^{n-1} \frac{d x}{d t} \\
\frac{d}{d t}\left(\frac{d x}{d t}\right)=\left[\frac{\beta E_{a}}{R T^{2}}-n A(1-x)^{n-1} \exp \left(-\frac{E_{a}}{R T}\right)\right] \frac{d x}{d t}
\end{gathered}
$$

The reaction rate $\frac{\mathrm{dx}}{\mathrm{dt}}$ will rise to a maximum value and then return to zero when the reactant is exhausted. The maximum rate occurs when $\frac{\mathrm{d}}{\mathrm{dt}}\left(\frac{\mathrm{dx}}{\mathrm{dt}}\right)$ is zero.

Then the equation 10 can be written as:

$$
\frac{\beta E_{a}}{R T_{m}^{2}}=n A(1-x)^{n-1} \exp \left(-\frac{E_{a}}{R T_{m}}\right)
$$

where $T_{m}$ is the reaction exothermic peak temperature. Assuming $\mathrm{n}=1$, then: ${ }^{[15]}$

$$
\frac{\beta E_{a}}{R T_{m}^{2}}=A \exp \left(-\frac{E_{a}}{R T_{m}}\right)
$$

For $\mathrm{n} \neq 0$ and $\mathrm{n} \neq 1$, based on the Coats-Redfern approximation: ${ }^{[18,20]}$

$$
n(1-x)^{n-1} \approx 1+(\mathrm{n}-1)\left(\frac{2 R T_{m}}{E_{a}}\right)
$$

Furthermore, because of

$$
\frac{2 R T_{m}}{E_{a}}<<1
$$

Then

$$
\begin{gathered}
(\mathrm{n}-1)\left(\frac{2 R T_{m}}{E_{a}}\right) \approx 0 \\
n(1-x)^{n-1} \approx 1
\end{gathered}
$$

The equation 11 can also be written as:

$$
\frac{\beta E_{a}}{R T_{m}^{2}}=A \exp \left(-\frac{E_{a}}{R T_{m}}\right)
$$

Change the equation 12 to:

$$
\frac{\beta}{T_{m}^{2}}=\frac{A R}{E_{a}} \exp \left(-\frac{E_{a}}{R T_{m}}\right)
$$

Taking the natural logarithm on both sides of equation 17 , the Kissinger method is written as: ${ }^{[15]}$

$$
\ln \left(\frac{\beta}{T_{m}^{2}}\right)=\ln \left(\frac{A R}{E_{a}}\right)-\frac{E_{a}}{R T_{m}}
$$

Plot $\ln \left(\frac{\beta}{T_{m}^{2}}\right)$ versus $\frac{1}{T_{m}}$ and fit all data using a straight line, (5) then the slope $(k)$ and the intercept (b) of the line equals to $\frac{E_{a}}{R T_{m}}$ and $\ln \left(\frac{A R}{E_{a}}\right)$, respectively. Finally, the activation energy $\left(\mathrm{E}_{\mathrm{a}}\right)$ can be obtained by $-k$ multiply the gas constant $\mathrm{R}(8.314$ $\mathrm{J} \mathrm{mol}^{-1} \mathrm{~K}^{-1}$ ) and the Arrhenius pre-exponential factor (A)can be obtained by $\frac{b E_{a}}{R}$.

On the basis of the Kissinger method, several other kinetic methods have also been developed, such as KissingerAkahira-Sunose (KAS) method. ${ }^{[21]}$

Considering equation (8), the equation (3) can be written as:

Then

$$
\beta \frac{d x}{d T}=f(x) A \exp \left(-\frac{E_{a}}{R T}\right)
$$

$$
\frac{d x}{f(x)}=A \exp \left(-\frac{E_{a}}{R T}\right) d T
$$

Define $g(x)$ as the integral form of $f(x)$, then

$$
g(x)=\int_{0}^{x} \frac{d x}{f(x)}=\frac{A}{\beta} \int_{0}^{T} \exp \left(-\frac{E_{a}}{R T}\right) d T \equiv \frac{A E_{a}}{\beta R} p\left(\frac{E_{a}}{R}\right)
$$

where $p\left(\frac{E_{a}}{R}\right)$ is an approximation.

Taking the natural logarithm on both sides of equation 21 , we have:

$$
\ln g(x)=\ln \left(\frac{A E_{a}}{R}\right)-\ln \beta+\ln p\left(\frac{E_{a}}{R}\right)
$$

On the basis of the Coats-Redfern approximation: ${ }^{[20-22]}$ 
Table 1. Kinetic methods in thermal analysis

\begin{tabular}{|c|c|c|}
\hline Method & Equation & Ref. \\
\hline Kissinger & $\ln \left(\frac{\beta}{T_{m}^{2}}\right)=\ln \left(\frac{A R}{E_{a}}\right)-\frac{E_{a}}{R T_{m}}$ & [15] \\
\hline $\begin{array}{l}\text { Kissinger-Akahira-Sunose } \\
\text { (KAS) }\end{array}$ & $\ln \left(\frac{\beta}{T_{m}^{2}}\right)=\ln \left(\frac{A R}{g(x) E_{a}}\right)-\frac{E_{a}}{R T_{m}}$ & [21] \\
\hline Elder & $\ln \left(\frac{\beta}{T_{m}^{2}}\right)=\ln \left(\frac{A R}{E_{a}}\right)-\frac{E_{a}}{R T_{m}}+\ln \Phi_{m}$ & [24] \\
\hline $\begin{array}{l}\text { Ozawa/Flynn-Wall-Ozawa } \\
\text { (FWO) }\end{array}$ & $\log \beta=-0.4567 \frac{E_{a}}{R T}-2.315+\log \left(\frac{A E_{a}}{R}\right)-\log [g(x)]$ & [26] \\
\hline Friedman & $\ln \left(\beta \frac{d x}{d T}\right)=\ln [A f(x)]-\frac{E_{a}}{R T_{m}}$ & [27] \\
\hline Achar & $\ln \left(\frac{1}{f(x)} \frac{d x}{d T}\right)=\ln \left(\frac{A}{\beta}\right)-\frac{E_{a}}{R T_{m}}$ & [38] \\
\hline Coats-Redfern & $\ln \left(\frac{g(x)}{T_{m}^{2}}\right)=\ln \left(\frac{A R}{\beta E_{a}}\right)-\frac{E_{a}}{R T_{m}}$ & [20] \\
\hline Augis-Bennett/Boswell & $\ln \left(\frac{\beta}{T_{m}}\right)=-\frac{E_{a}}{R T_{m}}+$ constant & {$[30,31]$} \\
\hline Matusita-Sakka & $\begin{array}{c}\ln \left(\frac{\beta^{n}}{T_{p}^{2}}\right)=-\frac{m E_{a}}{R T_{p}}+\text { constant } \\
d \ln \beta\end{array}$ & [42] \\
\hline Crane & $\frac{1}{d\left(\frac{1}{T_{m}}\right)}=-\left(\frac{L_{a}}{n R}+2 T_{m}\right)$ & [36] \\
\hline
\end{tabular}

Note: $x$ is the conversion; $f(x)$ is the function of the conversion; $g(x)$ is the integral form of $f(x) ; A$ is the pre-exponential factor for the thermal reaction; $R$ is the gas constant; $E_{a}$ is the activation energy; $n$ is the empirical order of reaction; $\beta$ is the heating rate; $\mathrm{T}_{\mathrm{m}} / \mathrm{T}_{\mathrm{p}}$ is the reaction exothermic peak temperature; $\mathrm{m}$ in the Matusita-Sakka method represents the dimensionality of the crystalline phase.

Then

$$
p\left(\frac{E_{a}}{R}\right) \approx \frac{\exp \left(-\frac{E_{a}}{R T}\right)}{\left(\frac{E_{a}}{R T}\right)^{2}}
$$

$$
\ln \beta=\ln \left(\frac{A E_{a}}{R}\right)-\ln g(x)-\ln \left(\frac{E_{a}}{R T}\right)^{2}-\frac{E_{a}}{R T}
$$

Finally, KAS method can be written as: ${ }^{[21-23]}$

$$
\ln \left(\frac{\beta}{T_{m}^{2}}\right)=\ln \left(\frac{A R}{g(x) E_{a}}\right)-\frac{E_{a}}{R T_{m}}
$$

Similar as the Kissinger method, the plot of $\ln \left(\frac{\beta}{T_{m}^{2}}\right)$ versus $\frac{1}{T_{m}}$ will develop a straight line. Then the $\mathrm{E}_{\mathrm{a}}$ can be calculated by the gradient of the curve multiplication with the gas constant $\mathrm{R}$.

The Kissinger method depends on determining the single point reaction peak temperature; however, it's limited to the reactions that the $E_{a}$ obtained at the single point reaction peak temperature that is different with the one for the early or late portions. The KAS method based on assuming the process that following the same mechanism of reaction for a given conversion degree and it doesn't need to consider the conversion-dependent function.

Moreover, Elder has modified the Kissinger method as: ${ }^{[11,24]}$

$$
\ln \left(\frac{\beta}{T_{m}^{2}}\right)=\ln \left(\frac{A R}{E_{a}}\right)-\frac{E_{a}}{R T_{m}}+\ln \Phi_{m}
$$

where $\Phi_{m}$ is a correction term, which depends on the kinetic models: ${ }^{[11,24]}$

$$
\ln \Phi_{m}=-\frac{d f(x)}{d x}
$$

This modification tried to make the Kissinger method applicable to the full range of kinetic models ${ }^{[11]}$

\subsection{Ozawa Method}

The Ozawa method is another popular approach for determining kinetic parameters. It was developed by Takeo Ozawa in 1965. ${ }^{[16]}$ Similar as the Kissinger method, the Ozawa method also depends on a series of experiments that heating samples at several different heating rates. The kinetic parameters are also determinate by recording the reaction exothermic peak temperature at each heating rate.

Define

Then

$$
y=\frac{E_{a}}{R T}
$$

$$
d T=-\frac{E_{a}}{R y^{2}} d y
$$

The equation 29 can be written as:

$$
\frac{A}{\beta} \int_{0}^{T} \exp \left(-\frac{E_{a}}{R T}\right) d T=\frac{A E_{a}}{\beta R} \int_{0}^{y}\left[-\frac{\exp (-y)}{y^{2}}\right] d y
$$

Define

$$
p(y)=\int_{0}^{y}\left[-\frac{\exp (-y)}{y^{2}}\right] d y
$$

Because of

$$
g(x)=\int_{0}^{x} \frac{d x}{f(x)}
$$



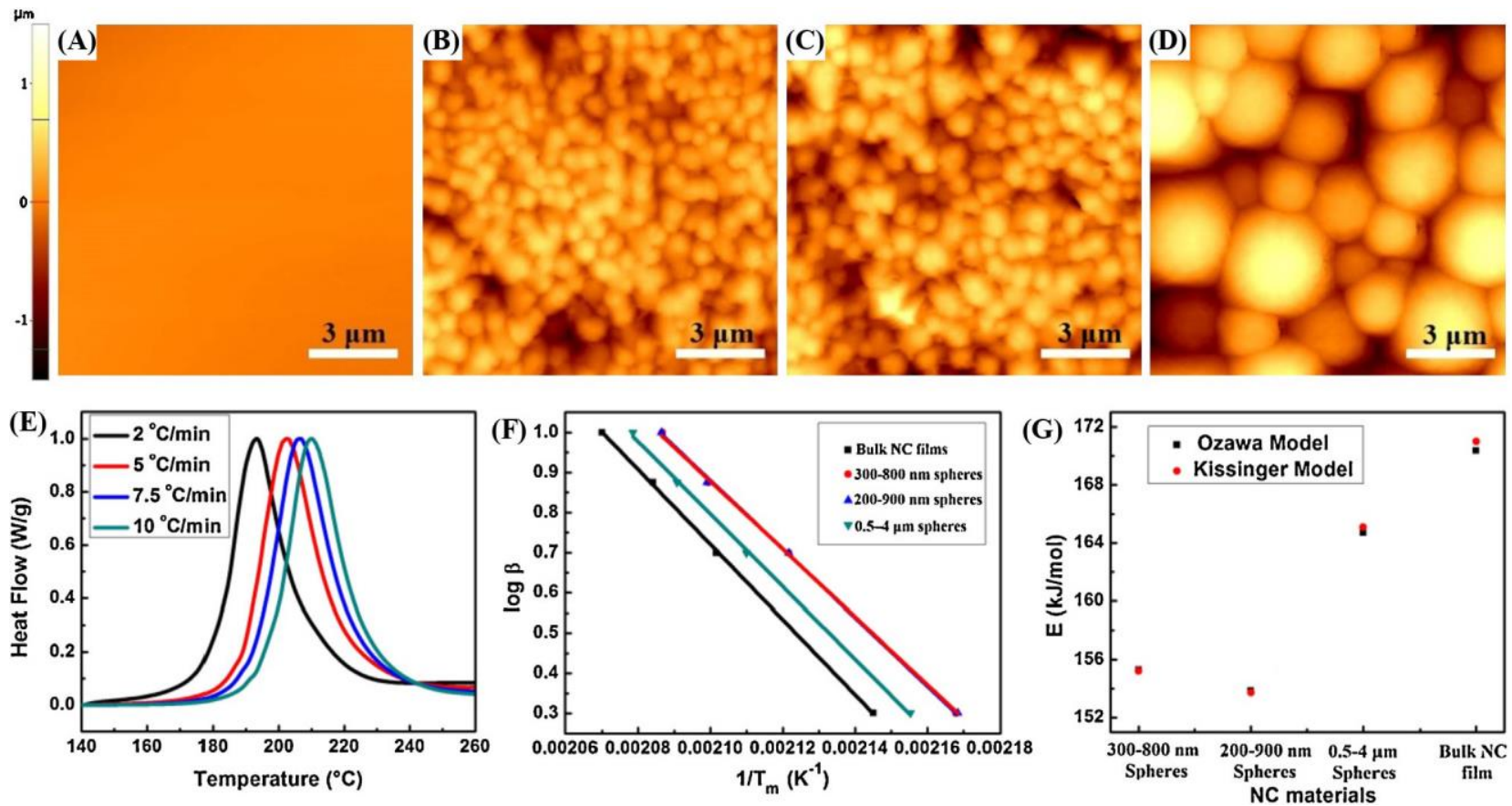

Fig. 1 AFM images of the different NC materials, which were prepared (a) from $10 \mathrm{mg} / \mathrm{mL}$ DMF solution at $25^{\circ} \mathrm{C}$ (bulk film), (b) from $5 \mathrm{mg} / \mathrm{mL}$ DMF solution at $5{ }^{\circ} \mathrm{C}(300-800 \mathrm{~nm})$, (c) from $10 \mathrm{mg} / \mathrm{mL}$ DMF solution at $5{ }^{\circ} \mathrm{C}(200-900 \mathrm{~nm})$, and (d) from $30 \mathrm{mg} / \mathrm{mL}$ DMF solution at $5{ }^{\circ} \mathrm{C}(0.5-4 \mu \mathrm{m})$. (E) DSC curves of bulk NC film at different heating rates; (F) plot of $\ln \beta$ versus the reciprocal of the peak temperature $1 / \mathrm{T}_{\mathrm{m}}$ (Ozawa method) for bulk NC film and NC samples that were constructed by $0.5-4 \mu \mathrm{m}, 200-900 \mathrm{~nm}$ and 300-800 nm particles; and (G) plot of activation energy of bulk NC film and NC samples that were constructed by 0.5-4 $\mu \mathrm{m}, 200$ $900 \mathrm{~nm}$ and 300-800 nm particles, reproduced with the permission from [44]. Copyright@ELSEVIER.

Then the equation 31 can be written as:

$$
g(x)=\frac{A E_{a}}{\beta R} p(y)
$$

Thus

$$
\beta=\frac{A E_{a}}{R g(x)} p(y)
$$

Taking the logarithm on both sides of equation 33 :

$$
\log \beta=\log \left(\frac{A E_{a}}{R}\right)-\log [g(x)]+\log p(y)
$$

Based on Doyle approximation, ${ }^{[25]}$

$$
\log p(y)=-2.315-0.4567 \frac{E_{a}}{R T}
$$

Then the Ozawa model can be written as: ${ }^{[25]}$

$$
\log \beta=-0.4567 \frac{E_{a}}{R T}-2.315+\log \left(\frac{A E_{a}}{R}\right)-\log [g(x)]
$$

Plot $\log \beta$ versus $\frac{1}{T_{m}}$ and fit all data using a straight line, then the activation energy $\mathrm{E}_{\mathrm{a}}$ can be obtained by $-\frac{\operatorname{Slope}(k) \cdot R}{0.4567}$. In 1966, Flynn and Wall reported a similar method with Ozawa's independently. ${ }^{[26]}$ Thus, the equation 36 is also called as FlynnWall-Ozawa (FWO) method.

Other kinetic methods, such as Friedman method, ${ }^{[27]}$ Friedman-Reich-Levi method, ${ }^{[28,29]}$ Augis-Bennett/Boswell method, ${ }^{[30,31]}$ Antić-Colović method, ${ }^{[32,33]}$ Sestak-Berggren method, ${ }^{[34,35]}$ Crane method, ${ }^{[36]}$ Moynihan method, ${ }^{[37]}$ Achar method, ${ }^{[38,39]}$ Coats-Redfern method, ${ }^{[20]}$ MadhusudananKrishnan-Ninan (MKN) method, ${ }^{[40]}$ and Borchardt-Daniels method $^{[41]}$ have also been developed to determine kinetic parameters. For some reactions, such as the crystallization with random nucleation, some modifications are necessary to these kinetic methods. All kinetic methods that discussed in this review are summarized in the Table 1 . We will further discuss these methods and their modifications in the application part.

\section{Applications of Kinetic Models in Thermal Analysis 3.1 Thermal decomposition}

The non-isothermal analysis is a popular method to explore the thermal decomposition reactions, such as thermal decomposition of energetic materials,${ }^{[43-48]}$ pyrolysis of biomass, ${ }^{[12,13,49,50]}$ and thermal degradation of minerals and plastics. ${ }^{[1,27,51,52]}$ Various kinetic methods, especially Kissinger and Ozawa methods, have been employed to obtain the kinetic parameters for thermal decomposition reactions. For example, Zhang et al. studied the effect of the particle size on the decomposition of nitrocellulose (NC) which is an important energetic material usually used as a propellant or explosive component via using the non-isothermal analysis technique. ${ }^{[44,53]}$ As shown in Fig 1A-D, they first synthesized NC bulk films and micro-structured films built by $300-800$ $\mathrm{nm}, 200-900 \mathrm{~nm}$, and $0.5-4 \mu \mathrm{m} \mathrm{NC}$ particles, respectively, via a solvent evaporation method. Then they explored the thermal properties of these films by using DSC with four heating rates of $2,5,7.5$ and $10{ }^{\circ} \mathrm{C} \mathrm{min}^{-1}$ in the temperature range of 40 $300{ }^{\circ} \mathrm{C}$. The decomposition kinetics are analyzed by Ozawa method first. As an example, the normalized DSC curves of 

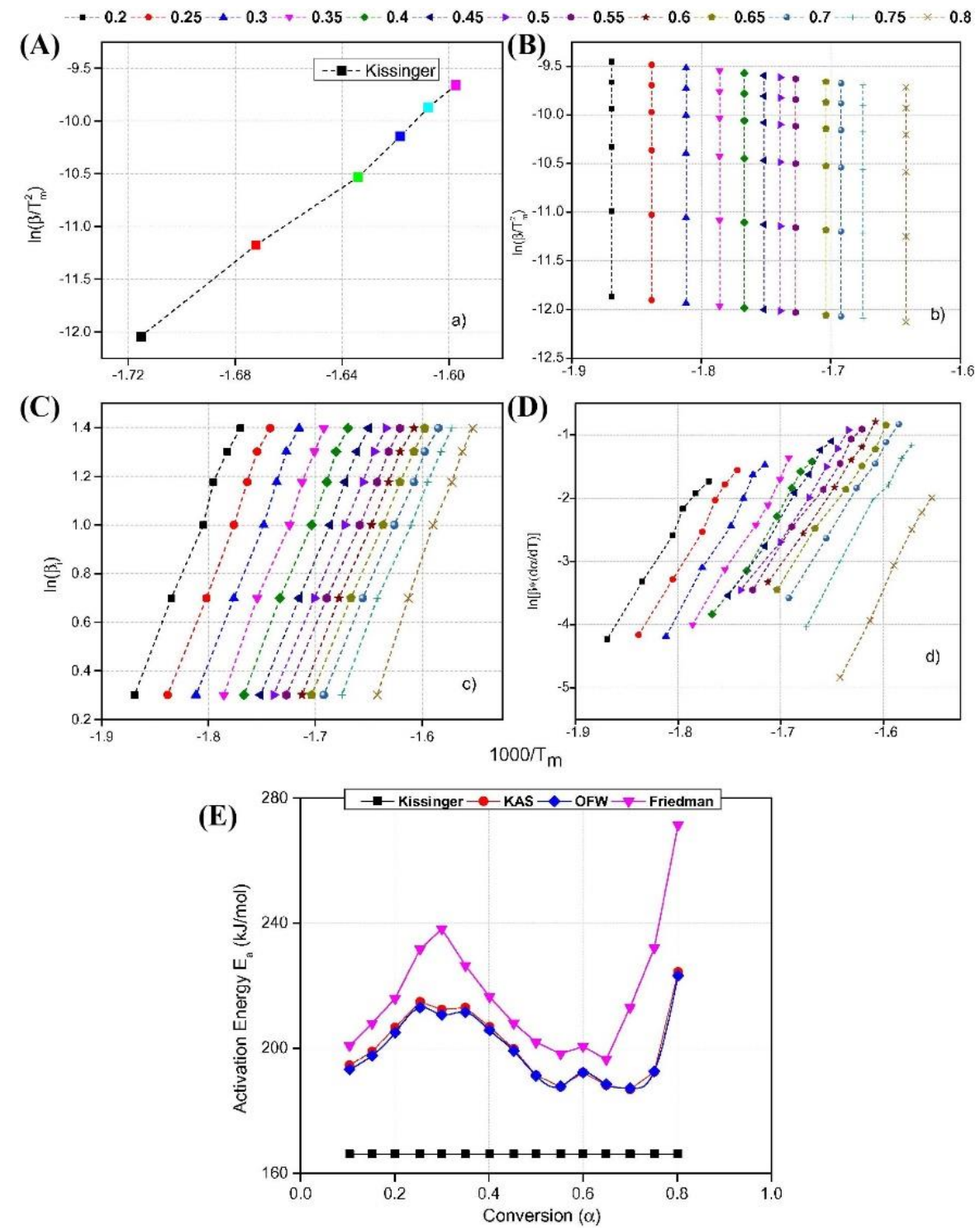

Fig. 2 Estimation of activation energy using different isoconversional methods (A) Kissinger, (B) KAS, (C) OFW, and (D) Friedman method; (E)Activation energy with function of conversion using different isoconversional techniques, reproduced with the permission from [49].Copyright@ELSEVIER.

the bulk NC sample at four different heating rates were plotted in Fig $1 \mathrm{E}$. Plot $\log \beta$ versus $1 / \mathrm{T}_{\mathrm{m}}$ and then fit all data using a straight line (Fig. 1F), the activation energies are obtained. The Kissinger method was also applied to calculate the $E_{a}$ for the thermal decomposition of all four samples. The $E_{a}$ obtained from both methods was plotted in Fig $1 \mathrm{G}$. Both methods demonstrated the same result that the $E_{a}$ of thermal decomposition of $\mathrm{NC}$ materials decreasing with decreasing particle size. There is no obviously difference for the values of $\mathrm{E}_{\mathrm{a}}$ obtained from both methods. Zhang et al. also investigated the effect of doping concentration of graphene oxide (GO) on the thermostability of $\mathrm{NC}$ using the non-isothermal analysis. ${ }^{[43]}$ The decomposition kinetics of pure $\mathrm{NC}$ and various GOdoped-NC samples were analyzed by both Kissinger and Ozawa methods too. Similar as the results obtained for exploring the size-dependent $\mathrm{NC}$ samples, both methods indicated the thermostability of $\mathrm{NC}$ increased obviously with increasing the doping concentration of GO and provided very close values of $E_{a}$ for the thermal decomposition of $\mathrm{NC}$. Moreover, He et al. investigated the thermal decomposition of pure $\mathrm{NC}$ and $\mathrm{NC}$ with different alcohol humectants such as 30 wt.\% isopropanol and 30 wt.\% ethanol via non-isothermal analysis. ${ }^{[46]}$ Similar as Zhang et al., He et al. also calculated the kinetic parameters via Kissinger and Ozawa methods and both methods provided similar results. The consistency in the calculation results for the $\mathrm{E}_{\mathrm{a}}$ of decomposition of $\mathrm{NC}$ and various NC-GO/alcohol mixtures indicated both Kissinger and Ozawa methods could be applied to determine the kinetic parameters of the simple decomposition reactions easily and fast.

For the complex thermal decomposition reactions, such as the pyrolysis of biomass, the KAS method and Friedman method are always employed to determine the kinetic parameters. ${ }^{[12,13,49,50]}$ As mentioned in the Part 2.1, unlike the 
Kissinger method, the KAS method assumed and rearranged mathematical approximation for exponential term. Generally, the KAS method could provide more accurate results than Kissinger method for the complex thermal decomposition reactions. Different with Kissinger, Ozawa/OFW, and KAS methods, Friedman method (Equation 37) is a differential form of algorithm. ${ }^{[27]}$

$$
\ln \left(\beta \frac{d x}{d T}\right)=\ln [A f(x)]-\frac{E_{a}}{R T_{m}}
$$

where $\mathrm{f}(\mathrm{x})$ is a constant for specified $\mathrm{x}$. Plot $\ln \left(\beta \frac{d x}{d T}\right)$ versus $\frac{1}{T_{m}}$ and fit all data using a straight line, the $\mathrm{E}_{\mathrm{a}}$ can be obtained by -slope $(\mathrm{k}) \cdot \mathrm{R}$.

Chandrasekaran et al. studied the thermal behavior of Prosopis Juliflora wood using TGA/DTG with six different heating rates of $2,5,10,15,20$ and $25^{\circ} \mathrm{C} / \mathrm{min}^{\left[{ }^{[49]}\right.}$ The $\mathrm{E}_{\mathrm{a}}$ of pyrolysis reaction was calculated using four different methods, including Kissinger (Fig. 2A), KAS (Fig. 2B), OFW (Fig. 2C) and Friedman (Fig. 2D) methods. ${ }^{[49]}$ The $E_{a}$ and preexponential factor (A) was calculated by the Kissinger method first, which is $164.58 \mathrm{~kJ} \mathrm{~mol}^{-1}$ and $1.67 \times 10^{5} \mathrm{~min}^{-1}$, respectively (Fig. 2E). Then the $\mathrm{E}_{\mathrm{a}}$ and A were determined by KAS, OFW and Friedman methods via giving a value of fractional conversion $(\alpha)$, which is ranging from 0.20 to 0.80 . The plots of these three methods were displayed in Fig 2B-D, respectively. The calculated $\mathrm{E}_{\mathrm{a}}$ in each $\alpha$ were plotted in Fig 2 E. Obviously, the $E_{a}$ was a function of $\alpha$, which varies from 187.1 to $231.2 \mathrm{~kJ} \mathrm{~mol}^{-1}$ for KAS method, 187.4 to $229.6 \mathrm{~kJ}$ $\mathrm{mol}^{-1}$ for OFW method, and 196.4 to $238.2 \mathrm{~kJ} \mathrm{~mol}^{-1}$ for Friedman method, respectively. The mean activation energies were 204, 203.2 and $219.3 \mathrm{~kJ} \mathrm{~mol}^{-1}$ for KAS, OFW and Friedman methods, respectively. If the decomposition occurred without a large variation in $\mathrm{E}_{\mathrm{a}}$ for a wide range of $\alpha$, then a uniformly reaction was assumed during processing. Otherwise, a complex reaction mechanism should be proposed. As shown in Fig 2E, significant changes of $E_{a}$ consistent with $\alpha$ indicated the whole decomposition process was complex and did not follow the same reaction mechanism for different conversion. The pre-exponential factor A also changed with $\alpha$; the average value was $1.4 \times 10^{10}, 1.5 \times 10^{4}$, and $6.8 \times 10^{20} \mathrm{~s}^{-1}$ for KAS, OFW and Friedman methods, respectively. Among all four methods, the $E_{a}$ calculated through Friedman method was independent of the heating rates, which could reduce the system error via evaluating the $\mathrm{E}_{\mathrm{a}}$. Thus, the Friedman method could be considered as the best one among these four methods to determine the kinetic parameters for the pyrolysis of biomass. ${ }^{[49]}$

Other kinetic methods, such as Achar [38,39] and CoatsRedfern methods, ${ }^{\text {,20] }}$ have also been developed to determine kinetic parameters for thermal decomposition processes. Achar method is a differential form, which is similar as Friedman method and can be presented as:

$$
\ln \left(\frac{1}{f(x)} \frac{d x}{d T}\right)=\ln \left(\frac{A}{\beta}\right)-\frac{E_{a}}{R T_{m}}
$$

Plot $\ln \left(\frac{1}{f(x)} \frac{d x}{d T}\right)$ versus $\frac{1}{T_{m}}$ and fit all data by a straight line, the $\mathrm{E}_{\mathrm{a}}$ can be calculated by -Slope $(k) \cdot \mathrm{R}$. The Arrhenius pre-exponential factor A will be obtained via intercept.

Coats-Redfern method is an integral form and can be written as:

$$
\ln \left(\frac{g(x)}{T_{m}^{2}}\right)=\ln \left(\frac{A R}{\beta E_{a}}\right)-\frac{E_{a}}{R T_{m}}
$$

Similar as the Kissinger and KAS methods, the plot of $\ln \left(\frac{g(x)}{T_{m}^{2}}\right)$ versus $\frac{1}{T_{m}}$ will develop a straight line. Then the $\mathrm{E}_{\mathrm{a}}$ equal to -Slope $(k) \cdot \mathrm{R}$. The Arrhenius pre-exponential factor A will be obtained via intercept too.

Bai et al. explored the thermal decomposition kinetics of light-weight composite $\mathrm{NaNH}_{2}-\mathrm{NaBH}_{4}$ hydrogen storage materials and the effect of Co-B doping via using both Achar and Coats-Redfern methods. ${ }^{[39]}$ The calculated $\mathrm{E}_{\mathrm{a}}$ for the pristine $\mathrm{NaNH}_{2}-\mathrm{NaBH}_{4}$ (2/1 molar rate) was around 159.6 $\mathrm{kJ} / \mathrm{mol}$, while the $\mathrm{E}_{\mathrm{a}}$ for the $\mathrm{Co}-\mathrm{B}$ doped $\mathrm{NaNH}_{2}-\mathrm{NaBH}_{4}(2 / 1$ molar rate) was $70 \mathrm{~kJ} / \mathrm{mol}$, which was only $43.9 \%$ of the former, This result indicated the thermal decomposition of $\mathrm{NaNH}_{2}-\mathrm{NaBH}_{4}$ was improved significantly via adding Co-B catalyst.
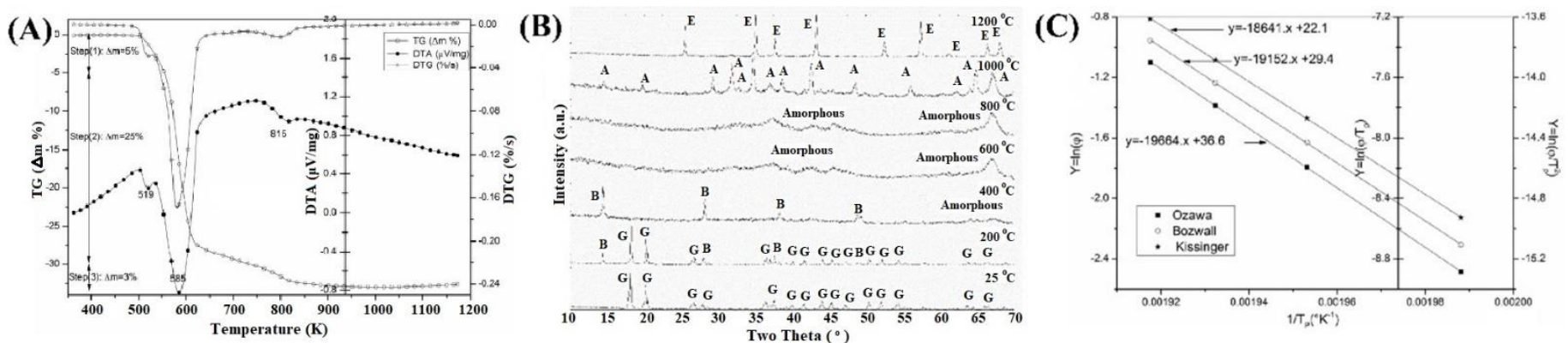

Fig. 3 (A) DTA and TG/DTG curves of gibbsite powder heated at $20{ }^{\circ} \mathrm{C} \min ^{-1}$. (B) XRD pattern of gibbsite powder treated at different temperatures for $2 \mathrm{~h}\left(\mathrm{G}\right.$ : Gibbsite, B: Boehomite, $\mathrm{A}: \chi-\mathrm{Al}_{2} \mathrm{O}_{3}$ and $\left.\mathrm{E}: \gamma-\mathrm{Al}_{2} \mathrm{O}_{3}\right)$. Note: Based on the literatures, the amorphous phase in the XRD pattern collected at 400 and $600-800{ }^{\circ} \mathrm{C}$ should be $\chi-\mathrm{Al}_{2} \mathrm{O}_{3}$ and $\gamma-\mathrm{Al}_{2} \mathrm{O}_{3}$, respectively; the phase $\mathrm{A}$ and $\mathrm{E}$ in the XRD pattern collected at 1000 and $1200{ }^{\circ} \mathrm{C}$ should be crystalline $\gamma-\mathrm{Al}_{2} \mathrm{O}_{3}$ and $\alpha-\mathrm{Al}_{2} \mathrm{O}_{3}$, respectively. $[80,81](\mathrm{B}) \mathrm{Plot}$ of $\mathrm{y}=\ln \beta, \ln \left(\beta / \mathrm{T}_{\mathrm{m}}\right)$ and $\ln \ln \left(\beta / \mathrm{T}_{\mathrm{m}}{ }^{2}\right)$ according to OFW, Boswell (Augis-Bennett), and KAS methods, respectively, reproduced with the permission from [55]. Copyright@Polish Academy of Sciences Institute of Physics. 




Fig. 4 Activation energy of crystallization vs. alloying time for $\mathrm{Ti}_{40} \mathrm{Zr}_{40} \mathrm{Ni}_{20}$ and $\mathrm{Ti}_{40} \mathrm{Hf}_{40} \mathrm{Ni}_{20}$ materials, reproduced with the Permission from [82]. Copyright@ELSEVIER.

\subsection{Solid Phase Transformation}

The kinetic parameters of the solid-state phase transformation reactions such as mineral, alloy glass and pharmaceutical ingredient phase transformations are always obtained via using non-isothermal technique. ${ }^{[54-60]}$ Except the Kissinger and Ozawa methods, a special method that only suitable for investigating heterogeneous solid-state reactions was developed based on Avrami law (Equation 40), which could be used to describe most solid phase transformation reactions

$$
x=1-\exp \left[-(k t)^{n}\right]
$$

where $x$ is the amount of material transformed at the time $t$, $n$ is a dimensionless exponent, $k$ is given by the Arrhenius equation. ${ }^{[30]}$

In 1978, J. A. Augis and J. E. Bennett developed the method first: ${ }^{[30]}$ then in 1980 , Boswell built the similar model independently: ${ }^{[31]}$

$$
\ln \left(\frac{\beta}{T_{m}}\right)=-\frac{E_{a}}{R T_{m}}+\text { constant }
$$

The Augis-Bennett/Boswell method depends on plotting $\ln \left(\frac{\beta}{T_{m}}\right)$ versus $\frac{1}{T_{m}}$ and fitting all data using a straight line. The activation energy $E_{a}$ can be obtained by -slope $(k) \cdot R$.

Redaoui et al. investigated the kinetic parameters for the solid phase transformation of gibbsite (aluminum hydroxide, $\left.\alpha-\mathrm{Al}(\mathrm{OH})_{3}\right)$ to alumina via using the non-isothermal technique. ${ }^{[55]}$ Gibbsite is one of the most abundant natural ores of aluminum, as well as an important raw material in industrials for catalysts, adsorbents, fire retardants, coatings, etc. ${ }^{[61-68]}$ It's also serve as an important precursor for the synthesis of boehmite (aluminum oxyhydroxide, $\gamma-\mathrm{AlOOH})^{[69}$ ${ }^{70]}$ and various alumina materials, such as chi $(\chi)-\mathrm{Al}_{2} \mathrm{O}_{3}$ and $\alpha$ $\mathrm{Al}_{2} \mathrm{O}_{3},{ }^{[63,71]}$ which are widely used in specialized industries including filler, catalysis, glass, ceramics, purification, paint, coating, and metallurgy. ${ }^{[72,73]}$ Moreover, gibbsite is one of the major components in nuclear wastes stored at the Hanford site
(WA, USA) and at the Savannah River site (SC, USA). ${ }^{[74-79]}$ Understanding the solid-state phase transformation of the gibbsite could help to improve the processes related to both nuclear waste treatment and alumina materials synthesis. As shown in Fig 3A, there are three steps for the solid phase transformation of gibbsite to alumina based on the DTA and TG/DTG curves. Combined with the XRD studies (Fig. 3B), the first and the smallest endothermic peak located at $519 \mathrm{~K}$ was assigned to the dehydroxylation of gibbsite to transfer to boehmite $(\gamma-\mathrm{AlOOH})$ partly; the peak at $585 \mathrm{~K}$ was contributed to two reactions: first is the additional transformation of the gibbsite to boehmite and second is the conversion of gibbsite to $\chi-\mathrm{Al}_{2} \mathrm{O}_{3}$; and the last endothermic peak at $815 \mathrm{~K}$ was claimed as the transformation of the boehmite to $\gamma-\mathrm{Al}_{2} \mathrm{O}_{3}$. There are four heating rates, including 5 , 10,15 and $20^{\circ} \mathrm{C}$, used to determine the kinetic parameters for all three steps. The activation energy $E_{a}$ for all three steps was calculated by using OFW, Boswell and KAS methods. The Fig $3 \mathrm{C}$ demonstrated the data fitting for the first step reaction at $519 \mathrm{~K}$. The value of the $\mathrm{E}_{\mathrm{a}}$ for these three steps was 154.9159.2, 248.8-256.9, and 277-285 $\mathrm{kJ} \mathrm{mol}^{-1}$, respectively, which agreed well with the isothermal techniques. Among these three kinetic methods, the Boswell method provided the highest $\mathrm{E}_{\mathrm{a}}$ for all three steps and the values were closer to the ones obtained from the isothermal techniques.

Friedman method (Equation 37) was also used to detect the kinetic parameters of the solid-state phase transformation reactions. For example, Prokof'ev et al. explored the kinetics of non-isothermal solid-state phase transformation of $\mathrm{ZnO}$ gibbsite and $\mathrm{Zn}_{4} \mathrm{CO}_{3}(\mathrm{OH})_{6} \cdot \mathrm{H}_{2} \mathrm{O}$-gibbsite using Friedman method and FWO method. ${ }^{[56,57]}$ Similar as the work reported by Redaoiu et al., Prokof'ev et al. also observed three peaks from DSC and DTG curves during heating $\mathrm{ZnO} / \mathrm{Al}(\mathrm{OH})_{3}$ mixtures from room temperature to $800{ }^{\circ} \mathrm{C}$. The endothermic effect for the temperature range of $200-400$ and $450-550{ }^{\circ} \mathrm{C}$ corresponded to transformation of gibbsite to boehmite and boehmite to alumina products, respectively. There is no peak assigned to the transformation of $\mathrm{ZnO}$. They only determined the kinetic parameters for the transformation of boehmite to alumina. The Friedman method was applied first. The kinetic curves based on Friedman method were obtained after numerical differentiation. A series of straight lines were also developed based on the OFW. Then the activation energies and pre-exponential factors were calculated via fitting the curves that plotted by Friedman and OFW methods. The values of activation energies obtained from Friedman and OFW methods were very close and have similar changing trends according to the conversion degree. Compared with the original mixture, the co-grinding samples owned lower activation energies at the final stages of the reaction (conversion degree $>0.5$ ), which indicated the co-grinding process could promote the solid-state phase transformation reactions. The similar results were obtained for the function of pre-exponential factor versus conversion degree. In addition, the values of $\ln$ Ao calculated from the OFW method was 10 
$20 \%$ larger than the values calculated from the Friedman method.

\subsection{Crystallization}

Non-isothermal analysis techniques have also usually been used to investigate the crystallization kinetics, such as the amorphous-to-quasicrystalline transformations in the alloy systems, ${ }^{[3,82]}$ crystallization of polymers/polymer-based nanocomposites, ${ }^{[4,83-88]}$ and nanocrystal formation in xyfluoride glass systems. ${ }^{[89]}$ Non-isothermal experiments, which using a fixed heating rate until the crystallization process completed, are frequently performed to obtain the crystallization temperature. Then the kinetic models were employed to calculate the kinetic parameters, such as the $E_{a}$ for crystallization. The most popular methods used to explore the crystallization process are also Kissinger method and Ozawa method. For the solid-state transformation-based crystallization, the Augis-Bennett/Boswell method is also used to obtain the kinetic parameters. But for the crystallization with random nucleation, a modified Kissinger method (Equation 42) developed by Matusita and Sakka is always applied to determine the kinetic parameters. ${ }^{[42]}$

$$
\ln \left(\frac{\beta^{n}}{T_{p}^{2}}\right)=-\frac{m E_{a}}{R T_{p}}+\text { constant }
$$

where $\mathrm{m}$ represents the dimensionality of the crystalline phase and $\mathrm{n}$ is the Avrami time exponent, which is determined from the Ozawa equation:

$$
\frac{d\{\ln [-\ln (1-X)]\}}{d \ln \beta}=-n
$$

where $\mathrm{X}$ is the volume fraction crystallized at a fixed temperature $\mathrm{T}$ when heated at heating rate $\beta$.

For example, Kocjan et al. explored the crystallization kinetics of $\mathrm{Ti}-\mathrm{Zr}-\mathrm{Ni}-$ and $\mathrm{Ti}-\mathrm{Hf}-\mathrm{Ni}$-based quasicrystals via using DSC integrating with XRD to detect the structural changes. ${ }^{[82]}$ To obtain the kinetic parameters, the alloys were heated up to $700{ }^{\circ} \mathrm{C}$ with five heating rates, including $2,5,10$, 15 and $20^{\circ} \mathrm{C} \mathrm{min}^{-1}$. The Kissinger model was used to calculate

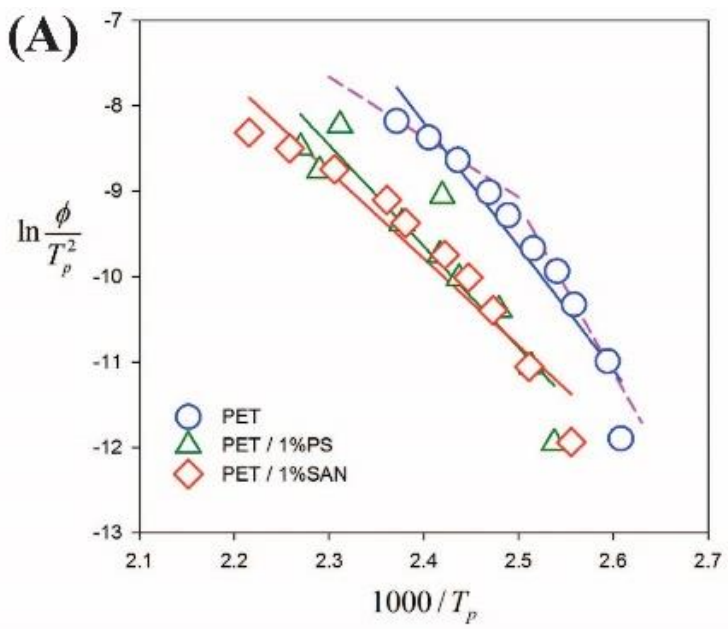

the $E_{a}$ for the crystallizations of different alloys first. Authors mentioned that the Kissinger model is only valid when the crystal growth occurs on a fixed number of nuclei. Then they also applied Matusita-Sakka method to obtain the $\mathrm{E}_{\mathrm{a}}{ }^{[42]}$ The calculated $E_{a}$ from both the Kissinger and the modified Kissinger methods were plotted in Fig 4. Although the value of the $E_{a}$ obtained from different method was totally different, both indicated the crystallization of $T i_{40} \mathrm{Zr}_{40} \mathrm{Ni}_{20}$ was much harder than $\mathrm{Ti}_{40} \mathrm{Hf}_{40} \mathrm{Ni}_{20}$. In addition, the result indicated the longer mechanically alloying time could make the crystallization easier.

Wellen et al. studied the nonisothermal crystallization of polyethylene terephthalate (PET) and its blends with $1 \%$ polystyrene (PS) and $1 \%$ styrene-acrylonitrile (SAN) copolymer using DSC with ten different heating rates, including $1,2.5,5,7.5,10,15,20,30,40$, and $50{ }^{\circ} \mathrm{C} \mathrm{min}^{-1}$. $^{[84]}$ The Kissinger model was used to calculate the $\mathrm{E}_{\mathrm{a}}$ for all samples first (Fig. 5A). However, the data fitting in the Fig 5A was poor based on all ten heating rates for all samples by using the linear Kissinger relationship between $\ln \left(\beta / T_{p}{ }^{2}\right)$ and $1 / T_{p}$, where $T_{p}$ is the detected crystallization temperature by DSC at different heating rates. In fact, nice fitting could be applied for both lower heating rates $\left(1,2.5,5\right.$, and $\left.7.5^{\circ} \mathrm{C} \mathrm{min}^{-1}\right)$ and higher heating rates $\left(20,30,40\right.$, and $\left.50{ }^{\circ} \mathrm{C} \mathrm{min}^{-1}\right)$, but provide different $E_{a}$, which is 165 and $85 \mathrm{~kJ} \mathrm{~mol}^{-1}$, respectively, for the crystallization of PET (broken lines in Fig. 5A). The calculated $\mathrm{E}_{\mathrm{a}}$ for the crystallization of PET based on 10 heating rates was $120 \mathrm{~kJ} \mathrm{~mol}^{-1}$. The Matusita-Sakka method, which using $\beta^{\mathrm{n}}$ to replace the $\beta$ in the Kissinger model, was also applied to obtain the $\mathrm{E}_{\mathrm{a}}$. The $\mathrm{n}$ for the PET, PET/1\% PS and $\mathrm{PET} / 1 \% \mathrm{SAN}$ was around $1,1.53$, and 2.27. There is no need to re-plot the data for PET due to the value of $m$ was around 1 . The obtained $E_{a}$ for the crystallization of PET/1\% PS and PET/1\% SAN was 115 and $160 \mathrm{~kJ} \mathrm{~mol}^{-1}$, respectively (Fig. $5 \mathrm{~B})$. These values were totally different with the one obtained from the traditional Kissinger model, which was 100 and 85 $\mathrm{kJ} \mathrm{mol}^{-1}$ for PET/1\% PS and PET/1\% SAN, respectively.

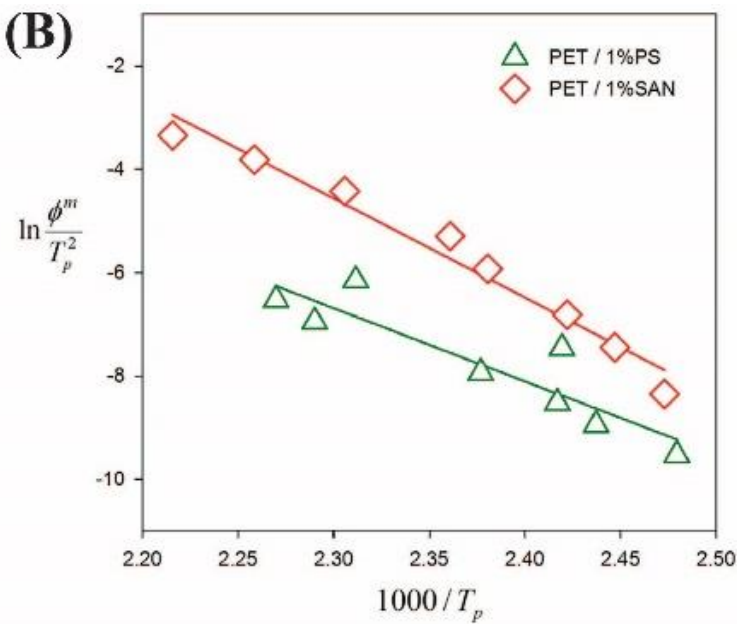

Fig. 5 Kissinger (A) and modified Kissinger (B) plots to calculate the $E_{a}$ for the cold crystallization of PET, PET/1\%PS, and PET/1\%SAN, reproduced with the Permission from [84]. Copyright@ELSEVIER. 

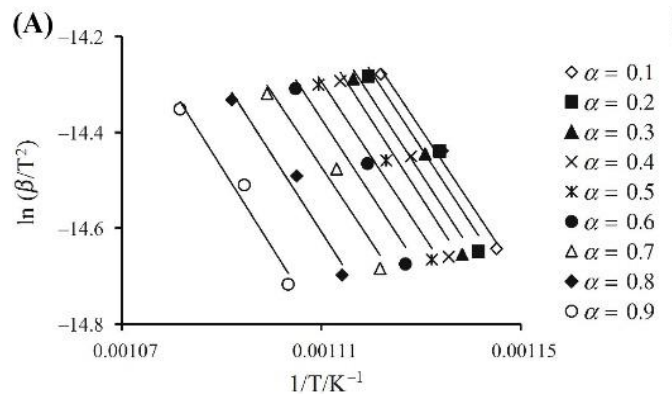

(B)

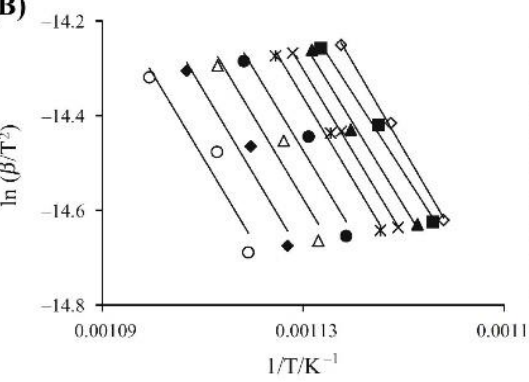

(C)

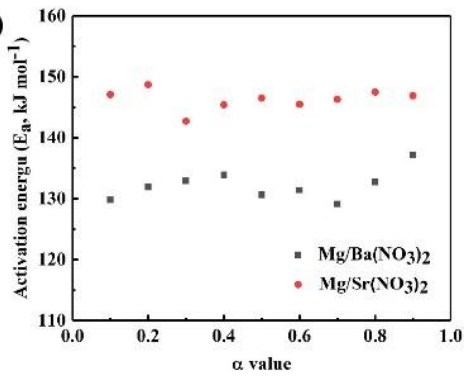

Fig. $6 \mathrm{KAS}$ plots for ignition reaction of $(\mathrm{A}) \mathrm{Mg} / \mathrm{Ba}\left(\mathrm{NO}_{3}\right)_{2}$ and (B) $\mathrm{Mg} / \mathrm{Sr}\left(\mathrm{NO}_{3}\right)_{2}$ pyrotechnic at three heating rates and various conversion factors $\left(\alpha=0.1-0.9\right.$, with 0.1 increment). (C) The calculated $\mathrm{E}_{\mathrm{a}}$ from the KAS methods for various conversion factors, reproduced with the Permission from [90]. Copyright@Springer.

\subsection{Ignition reaction}

Thermal induced ignition reactions have also been investigated by using various kinetic methods. ${ }^{\text {[90-92] }}$ For example, Pouretedal et al. explored the ignition reactions $\mathrm{Mg} / \mathrm{Ba}\left(\mathrm{NO}_{3}\right)_{2}$ and $\mathrm{Mg} / \mathrm{Sr}\left(\mathrm{NO}_{3}\right)_{2}$ (Equation 44) via using the non-isothermal thermal analysis technique. ${ }^{[90]}$ The TG/DSC curves were obtained at three heating rates of 20,25 and $30{ }^{\circ} \mathrm{C}$ $\min ^{-1}$ under nitrogen atmosphere. The Kissinger and FWO methods were employed to calculate the $E_{a}$ of ignition reactions of $\mathrm{Mg} / \mathrm{Ba}\left(\mathrm{NO}_{3}\right)_{2}$ and $\mathrm{Mg} / \mathrm{Sr}\left(\mathrm{NO}_{3}\right)_{2}$ pyrotechnics first, which is 130.5 and $146.3 \mathrm{~kJ} \mathrm{~mol}^{-1}$, and 138.3 and $153.2 \mathrm{~kJ} \mathrm{~mol}^{-}$ 1 , respectively. Then the KAS method was applied to obtain the $E_{a}$ at a wide range of $\alpha(0.1$ to 0.9$)$. The Fig $6 \mathrm{~A}$ and $6 \mathrm{~B}$ displayed the KAS plots for these ignition reactions at three heating rates and various conversion factors. The calculated $\mathrm{E}_{\mathrm{a}}$ was plotted in Fig 6C. There were no significantly change in the $E_{a}$ with changing the $\alpha$, which indicated both ignition reactions were uniform.

$$
\begin{array}{r}
3 \mathrm{Mg}(\mathrm{s})+\mathrm{M}\left(\mathrm{NO}_{3}\right)_{2}(\mathrm{~s}) \longrightarrow 3 \mathrm{MgO}(\mathrm{s})+\mathrm{MO}(\mathrm{s})+\mathrm{N}_{2}(\mathrm{~g}) \\
+\mathrm{O}_{2}(\mathrm{~g})(\mathrm{M}=\mathrm{Ba} \text { or } \mathrm{Sr})
\end{array}
$$

Pouretedal et al. also investigated the catalytic effect of $\mathrm{Ag} / \mathrm{multi}$-walled carbon nanotubes (CNTs) nanocomposite on the ignition reactions of $\mathrm{Mg} / \mathrm{KNO}_{3}$ pyrotechnics via the thermal analysis technique. ${ }^{[91]}$ The DSC with heating rates of

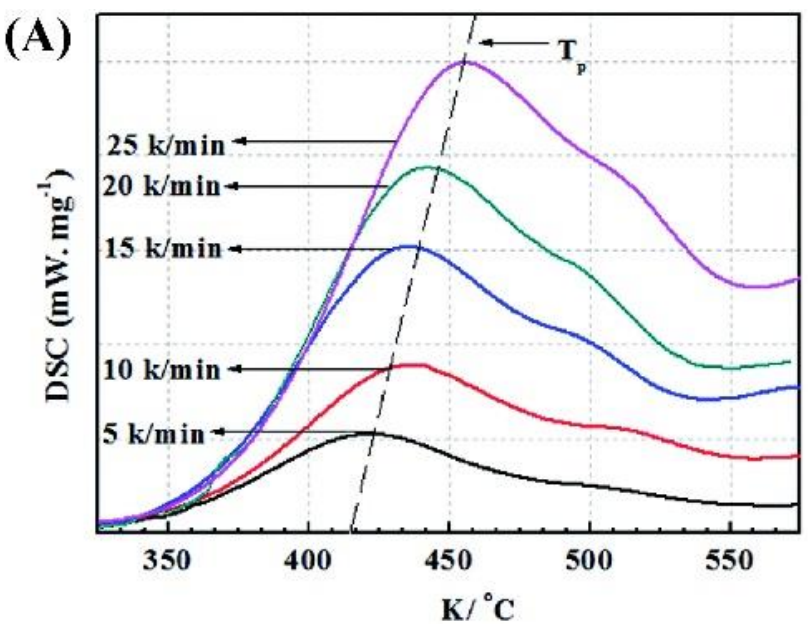

5, 10, 15 and $20{ }^{\circ} \mathrm{C} \min ^{-1}$ was performed to determine the exothermic peaks of ignition reactions of $\mathrm{Mg} / \mathrm{KNO}_{3}$ and $\mathrm{Mg} / \mathrm{KNO}_{3} / \mathrm{Ag} / \mathrm{CNTs}$ under $\mathrm{N}_{2}$ atmosphere. There was a decrease around $37^{\circ} \mathrm{C}$ in exothermic peak temperature and an increase around $500 \mathrm{~J} \mathrm{~g}^{-1}$ in enthalpy after introducing $\mathrm{Ag} / \mathrm{CNT}$ into $\mathrm{Mg} / \mathrm{KNO}_{3}$. Using Kissinger, FWO and KAS methods, the $\mathrm{E}_{\mathrm{a}}$ of the ignition reaction of $\mathrm{Mg} / \mathrm{KNO}_{3}$ was calculated as $174.6 \pm 7.8 \mathrm{~kJ} \mathrm{~mol}^{-1}$; however, the value of the $\mathrm{E}_{\mathrm{a}}$ was reduced to $155.8 \pm 5.3 \mathrm{~kJ} \mathrm{~mol}^{-1}$ in presence of the $\mathrm{Ag} / \mathrm{CNTs}$, which indicated the ignition reaction of $\mathrm{Mg} / \mathrm{KNO}_{3}$ was improved obviously with adding $\mathrm{Ag} / \mathrm{CNTs}$ as catalyst.

\subsection{Curing process}

Obtain the kinetic parameters of the curing reactions has important theoretical and practical significance for its application in industrial. For example, the value of the $E_{a}$ could reflect the degree of difficulty in the curing process directly. ${ }^{[93]}$ To date, various kinetic methods have been employed to determine the kinetic parameters for curing processes. ${ }^{[17,23,36,93-96]}$ For instance, Ding et al. explored the curing reaction kinetics of the epoxy resin (EP)/3,6-enodro1,2,3,6-tetrahydrophthalic anhydride (OBPA)/Furfuryl glycidyl ether (FGE) polymer system via the non-isothermal DSC method (Fig. 7A). ${ }^{[93]}$ The Kissinger and Ozawa methods

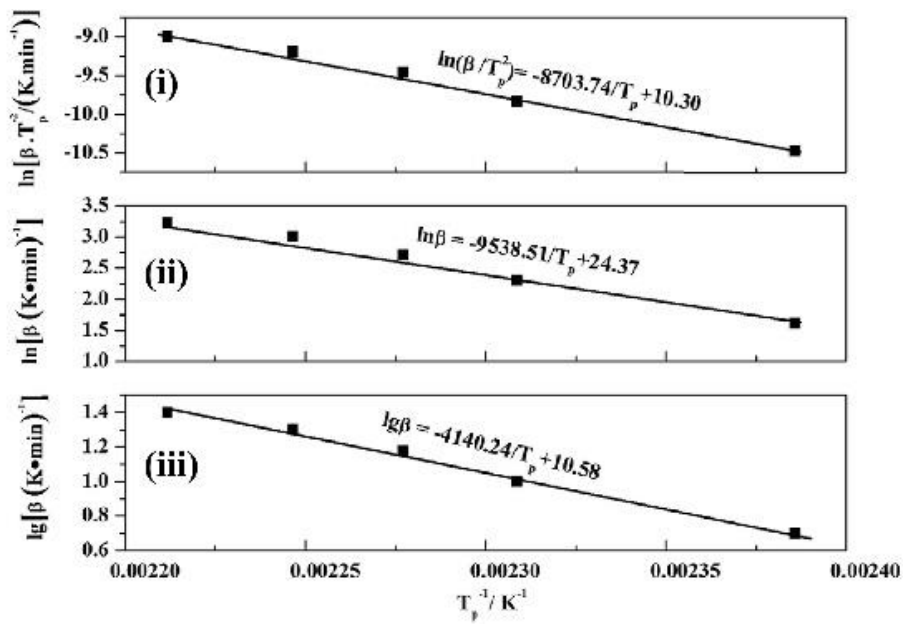

Fig. 7 (A) Non-isothermal DSC curves of EP/OBPA/FGE system. (B) The relation between $\left(\beta / \mathrm{T}_{\mathrm{p}}{ }^{2}\right)$ and $1 / \mathrm{T}_{\mathrm{p}}$ of Kissinger (i), the relation between $\ln \beta$ and $1 / T_{p}$ of Crane (ii), and the relation between $\lg \beta$ and $1 / T_{p}$ of Ozawa (iii), reproduced with the Permission from [93]. Copyright@Royal Society of Chemistry. 
were applied to obtain the $E_{a}$ first, then the Crane method was employed to determine the reaction order (Fig. 7B).

The Crane method was presented as: ${ }^{[36]}$

$$
\frac{d \ln \beta}{d\left(\frac{1}{T_{m}}\right)}=-\left(\frac{E_{a}}{n R}+2 T_{m}\right)
$$

A plot of $\ln \beta$ versus $\frac{1}{T_{m}}$ will generate a straight line with the slope $\left(-\frac{E_{a}}{n R}\right)$ when $\frac{E_{a}}{n R}>2 T_{m}$. Then the reaction order $\mathrm{n}$ equal to $\left(-\frac{E_{a}}{\operatorname{slope}(k) \cdot R}\right)$. Based on the Kissinger method and Ozawa method, the $E_{a}$ of the curing reaction was 72.37 and $73.87 \mathrm{~kJ} \mathrm{~mol}^{-1}$, respectively, both indicated $\frac{E_{a}}{n R}>$ $>2 T_{m}$. The slope of the line that obtained by fitting the plot of $\ln \beta$ versus $\frac{1}{T_{m}}$ is -9538.51 , then the reaction order $\mathrm{n}$ is 0.912 or 0.931 , which was a first order reaction. The value of pre-exponential factor $A$ was calculated as $2.640 \times 10^{8} \mathrm{~min}^{-1}$.

Moreover, the non-isothermal analysis based kinetic methods have also been used to determine the kinetic parameters for the melting, ${ }^{[97,98]}$ combustion, ${ }^{[2,99]}$ aging process, ${ }^{[100]}$ etc.

\section{Conclusions}

Various non-isothermal kinetic methods, which depends on relationships between heating rates and temperatures that the reaction reaches a maximum value, have been developed to obtain kinetic parameters for different thermal reactions. It's critical to choose suitable or develop novel kinetic methods for the thermal analysis. Kissinger and Ozawa methods are most popular kinetic methods to determine the kinetic parameters and they're easy and fast, but both methods are limited to the simple reactions. The modifications are necessary for these kinetic methods when analyze the complex processes, such as the pyrolysis of biomass and the crystallization with random nucleation. The KAS and Matusita-Sakka methods have been developed to investigate complex reactions. The Friedman method is independent of the heating rates, which could reduce the system error via evaluating the $E_{a}$. Thus, the Friedman method could be considered as a better approach for some complex systems. In addition, some kinetic methods are developed to work on specific reactions, such as the AugisBennett/Boswell method for solid-state phase transformations and Crane method for determining reaction orders. Moreover, researches pointed out that some kinetic methods such as Kissinger method were derived only for heating experiments and were not mathematically sound for cooling processes. ${ }^{[101}$, ${ }^{102]}$ Employing these methods with positive values of cooling rates may lead to erroneous values of the activation energy. ${ }^{101}$ Although Kissinger method and other non-isothermal kinetic methods have been widely applied to determine the cooling processes, researchers should still pay attention to use these methods in their systems. It would be highly advisable to employ several non-isothermal kinetic methods to calculate the kinetic parameters and evaluate the differences from different methods.
It worth to point out that kinetic parameters can be determined easily and fast by fitting the thermal analysis data using different kinetic method, but the data analysis is also very subjective to the experimental design, instrument configuration, data collection, and even reacting atmosphere. Thus, it's critical to apply suitable non-isothermal technique for the thermal reactions based on literature retrieval and contrast analysis method. Finally, because of the limitation of the different kinetic models, there is a continuous interest in developing simple, practical or fast kinetic methods for nonisothermal analysis, especially for a particular type of thermal reaction but with high accuracy.

\section{Acknowledgements}

This work was supported by IDREAM (Interfacial Dynamics in Radiation Environments and Materials), an Energy Frontier Research Center funded by the U.S. Department of Energy (DOE), Office of Science, Basic Energy Sciences (BES).

\section{Support information}

Not applicable

\section{Conflict of Interest}

There are no conflicts to declare.

\section{References:}

[1] D. Ren, X. Liu, X. Feng, L. Lu, M. Ouyang, J. Li and X. He, Appl. Energy, 2018, 228, 633-644, doi: 10.1016/j.apenergy.2018.06.126.

[2] Z. Yao, S. Yu, W. Su, D. Wu, W. Wu and J. Tang, Waste Manag Res, 2020, 38, 100-106, doi: 10.1177/0734242X19879224.

[3] W. Li, Y. Z. Yang and J. Xu, J. Non-Cryst. Solids, 2017, 461, 93-97, doi:10.1016/j.jnoncrysol.2017.01.047.

[4] W. Weng, G. Chen and D. Wu, Polymer, 2003, 44, 81198132, doi:10.1016/j.polymer.2003.10.028.

[5] Y. Miyagawa, M. Yoshida, K. Nakagawa and S. Adachi, Cryst. Growth Des., 2018, 18, 642-650, doi: 10.1021/acs.cgd.7b00789.

[6] A. A. Boopathi, S. Sampath and T. Narasimhaswamy, New J. Chem., 2019, 43, 9500-9506, doi: 10.1039/C8NJ06514D.

[7] G. N. Lewis, Zeitschrift für Physikalische Chemie, 1905, 52, 310-326, doi: 10.1515/zpch-1905-5219.

[8] S. Vyazovkin and C. A. Wight, Int. Rev. Phys. Chem., 1998, 17, 407-433, doi: 10.1080/014423598230108.

[9] T. Ozawa, Thermochim. Acta, 2000, 355, 35-42, doi: 10.1016/S0040-6031(00)00435-4.

[10] Z. Zhang, J. Chen, H. Liu and C. Xiao, J. Therm. Anal. Calorim., 2014, 117, 783-787, doi: 10.1007/s10973-0143751-1.

[11] P. Budrugeac and E. Segal, J. Therm. Anal. Calorim, 2007, 88, 703-707, doi: 10.1007/s10973-006-8087-z. 
[12] S. Papari and K. Hawboldt, Renew. Sustain. Energy Rev., 2015, 52, 1580-1595, doi: 10.1016/j.rser.2015.07.191.

[13] Q. V. Bach and W. H. Chen, Bioresour Technol, 2017, 246, 88-100, doi: 10.1016/j.biortech.2017.06.087.

[14] H. Yinnon and D. R. Uhlmann, J. Non-Cryst. Solids, 1983, 54, 253-257, doi: 10.1016/0022-3093(83)90069-8.

[15] H. E. Kissinger, Anal. Chem., 1957, 29, 1702-1706, doi: 10.1021/ac60131a045.

[16] T. Ozawa, Bull. Chem. Sot. Jpn., 1965, 38, 1881-1886, doi: 10.1246/bcsj.38.1881.

[17] I.-K. Hong and S. Lee, J. Ind. Eng. Chem., 2013, 19, $42-$ 47, doi: 10.1016/j.jiec.2012.05.006.

[18] B. Jankovic, Chem. Eng. J., 2008, 139, 128-135, doi: 10.1016/j.cej.2007.07.085.

[19] S. Rana, J. K. Parikh and P. Mohanty, Korean J. Chem. Eng., 2012, 30, 626-633, doi:10.1007/s11814-012-0157-2.

[20] A. W. Coats and J. P. Redfern, Nature, 1964, 201, 68-69, doi: $10.1038 / 201068 \mathrm{a} 0$.

[21] T. Akahira and T. Sunose, Res. Rep. Chiba Inst. Technol., 1971, 16, 22-31.

[22] A. C. R. Lim, B. L. F. Chin, Z. A. Jawad and K. L. Hii, Procedia Eng., 2016, 148, 1247-125, doi: 10.1016/j.proeng.2016.06.486.

[23] J. M. Pérez, M. Oliet, M. V. Alonso and F. Rodríguez, Thermochim. Acta, 2009, 487, 39-42, doi: $10.1016 /$ j.tca.2009.01.005.

[24] J. P. Elder, J. Therm. Anal., 1985, 30, 657-669, doi: 10.1007/BF01913612.

[25] T. Ozawa, J. Therm. Anal., 1970, 2, 301-324, doi: 10.1007/BF01911411.

[26] J. H. Flynn and L.A. Wall, J. Polym. Sci. Part B, 1966, 4, 323-328, doi: 10.1002/pol.1966.110040504.

[27] H. Friedman, J. Polym. Sci. Part C, 1964, 6, 183-195, doi: 10.1002/polc.5070060121.

[28] L. Reich and D. W. Levi, J. Polym. Sci. Macromol. Rev., 1967, 1, 173-275. doi: 10.1002/pol.1967.230010106.

[29] H. L. Friedman, J. Polym. Sci. B Polym. Lett., 1969, 7, 41-46. doi: 10.1002/pol.1969.110070109.

[30] J. A. Augis and J. E. Bennett, J. Therm. Anal., 1978, 13, 283-292, doi: 10.1007/BF01912301.

[31] P. G. Boswell, J. Therm. Anal., 1980, 18, 353-358, doi: 10.1007/bf02055820.

[32] J. Perić, R. Krstulović, T. Ferić and M. Vučak, Themochim. Acta, 1992, 207, 245-254, doi: 10.1016/00406031(92)80140-R.

[33] M. Antić and N. Colović, Institut zaštite naradu, Niš, 1983, pp269-278, 285-390.

[34] J. Šesták and G. Berggren, Thermochim. Acta, 1971, 3, 1 12, doi: 10.1016/0040-6031(71)85051-7.
[35] G. Munteanu and E. Segal, J. Therm. Anal. Calorim, 2010, 101, 89-95, doi: 10.1007/s10973-009-0435-3.

[36] L. W. Crane, P. J. Dynes and D. H. Kaelable, J. Polym. Sci. Polym. Lett. Ed,, 1973, 11, 533-540, doi: 10.1002/pol.1973.130110808.

[37] C. T. Moynihan, A. J. Easteal, J. Wilder and J. Tucker, J.

Phys. Chem., 1974, 78, 2673-2677, doi: 10.1021/j100619a008. [38] B. N. Achar, G. W. Brindley and J. H. Sharp, Proc. Int. Clay Conf., Jerusalem, 1966, 1, 67.

[39] Y. Bai, C. Wu, F. Wu, J.-h. Yang, L.-1. Zhao, F. Long and B.-1. Yi, Int. J. Hydrog. Energy, 2012, 37, 12973-12979, doi: 10.1016/j.ijhydene.2012.05.069.

[40] P. M. Madhusudanan, K. Krishnan and K. N. Ninan, Thermochim. Acta, 1986, 97, 189-201, doi: 10.1016/00406031(86)87019-8.

[41] H. J. Borchardt and F. Daniels, J. Am. Chem. Soc., 1957, 79, 41-46, doi: 10.1021/ja01558a009.

[42] K. Matusita and S. Sakka, J. Non-Cryst. Solids, 1980, 38, 741, doi: 10.1016/0022-3093(80)90525-6

[43] X. Zhang, W. M. Hikal, Y. Zhang, S. K. Bhattacharia, L. Li, S. Panditrao, S. Wang and B. L. Weeks, Appl. Phys. Lett., 2013, 102, 141905, doi: 10.1063/1.4801846.

[44] X. Zhang and B. L. Weeks, J Hazard Mater, 2014, 268, 224-228, doi: 10.1016/j.jhazmat.2014.01.019.

[45] B. Zhao, T. Zhang, Z. Ge and Y. Luo, Sci. China Chem., 2015, 59, 472-477, doi: 10.1007/s11426-015-5538-Z.

[46] Y. He, Y. He, J. Liu, P. Li, M. Chen, R. Wei and J. Wang, $J$ Hazard Mater, 2017, 340, 202-212, doi: 10.1016/j.jhazmat.2017.06.029.

[47] X. Zhang and B. L. Weeks, J. Therm. Anal. Calorim., 2015, 122, 1061-1067, doi: 10.1007/s10973-015-5005-2.

[48] M. Ghosh, A. K. Sikder, S. Banerjee and R. G. Gonnade, Cryst. Growth Des., 2018, 18, 3781-3793, doi: 10.1021/acs.cgd.8b00015.

[49] A. Chandrasekaran, S. Ramachandran and S. Subbiah, Bioresour Technol, 2017, 233, 413-422, doi: 10.1016/j.biortech.2017.02.119.

[50] K. Midhun Prasad and S. Murugavelh, J. Clean. Prod., 2020, 254, 120115, doi:10.1016/j.jclepro.2020.120115.

[51] M. Vázquez, I. Moreno-Ventas, I. Raposo, A. Palma and M. J. Díaz, J. Therm. Anal. Calorim., 2019, 141, 1157-1163, doi: 10.1007/s 10973-019-09098-4.

[52] P. Das and P. Tiwari, Thermochim. Acta, 2017, 654, 191 202, doi: 10.1016/j.tca.2017.06.001.

[53] X. Zhang, K. S. Ziemer, and B. L. Adv. Compos. Hybrid Mater., 2019, 2, 492-500, doi: 10.1007/s42114-019-00113-8.

[54] N. Tanwar and V. K. Saraswat, J. Non-Cryst. Solids, 2014, 394-395, 1-5, doi: 10.1016/j.jnoncrysol.2014.03.029.

[55] D. Redaoui, F. Sahnoune, M. Heraiz and A. Raghdi, Acta 
Phys. Pol. A, 2017, 131, 562-565, doi:10.12693/APHYSPOLA.131.562.

[56] V. Y. Prokof'ev, N. E. Gordina and N. N. Smirnov, $J$. Therm. Anal. Calorim., 2015, 124, 159-170, doi: 10.1007/s10973-015-5054-6.

[57] V. Y. Prokof'ev, N. V. Petuhova and N. E. Gordina,Int. J. Chem. Kinet., 2015, 47, 576-585, doi: 10.1002/kin.20931.

[58] E. S. Lee and Y. G. Kim, Acta Mater., 1990, 38, 1677 1686, doi: 10.1016/0956-7151(90)90010-E.

[59] T. H. Grgurić, D. Manasijević, S. Kožuh, I. Ivanić, I. Anžel, B. Kosec, M. Bizjak, E. G. Bajsić, L. Balanović and M. Gojić, J. Alloys Compd., 2018, 765, 664-676, doi: 10.1016/j.jallcom.2018.06.250.

[60] Y. J. Lee, O. Pahom and B. L. Weeks, Cryst. Growth Des., 2019, 19, 932-941, doi: 10.1021/acs.cgd.8b01488.

[61] Y.-Y. Yen, H.-T. Wang and W.-J. Guo, J. Appl. Polym. Sci., 2013, 130, 2042-2048, doi: 10.1002/app.39394.

[62] N. Huittinen, T. Rabung, J. Lutzenkirchen, S. C. Mitchell, B. R. Bickmore, J. Lehto and H. Geckeis, J. Colloid Interface Sci., 2009, 332, 158-164, doi: 10.1016/j.jcis.2008.12.017.

[63] S. Louaer, Y. Wang and L. Guo, ACS Appl. Mater. Interfaces, 2013, 5, 9648-9655, doi: .1021/am402677v.

[64]R. Weerasooriya, W. Seneviratne, H. A. Kathriarachchi and H. J. Tobschall, J. Colloid Interface Sci., 2006, 301, 452460, doi: 10.1016/j.jcis.2006.05.054.

[65] R. Weerasooriya, H. J. Tobschall, H. K. D. K. Wijesekara, E. K. I. A. U. K. Arachchige and K. A. S. Pathirathne, Chemosphere, 2003, 51, 1001-1013, doi: 10.1016/S00456535(03)00157-7.

[66] X. Zhang, X. Zhang, T. R. Graham, C. I. Pearce, B. L. Mehdi, A. T. N'Diaye, S. Kerisit, N. D. Browning, S. B. Clark and K. M. Rosso, Cryst. Growth Des., 2017, 17, 6801-6808, doi: 10.1021/acs.cgd.7b01400.

[67] J. Z. Hu, X. Zhang, N. R. Jaegers, C. Wan, T. R. Graham, M. Hu, C. I. Pearce, A. R. Felmy, S. B. Clark and K. M. Rosso, J. Phys. Chem. C, 2017, 121, 27555-27562, doi: 10.1021/acs.jpcc.7b10424.

[68] S. Wang, X. Zhang, T. R. Graham, H. Zhang, C. I. Pearce, Z. Wang, S. B. Clark, W. Jiang and K. M. Rosso, CrystEngComm, 2020, 22, 2555-2565, doi: 10.1039/D0CE00114G.

[69] X. Zhang, W. Cui, K. L. Page, C. I. Pearce, M. E. Bowden, T. R. Graham, Z. Shen, P. Li, Z. Wang, S. N. Kerisit, A. T. N'Diaye, S. B. Clark and K. M. Rosso, Cryst. Growth Des., 2018, 18, 3596-3606, doi: 10.1021/acs.cgd.8b00394.

[70] X. Zhang, W. Cui, J. Z. Hu, H.-W. Wang, M. P. Prange, C. Wan, N. R. Jaegers, M. Zong, H. Zhang, C. I. Pearce, P. Li, Z. Wang, S. B. Clark and K. M. Rosso, Cryst. Growth Des., 2019, 19, 5557-5567, doi: 10.1021/acs.cgd.9b00468.
[71] Zhang, P. L. Huestis, C. I. Pearce, J. Z. Hu, K. Page, L. M. Anovitz, A. B. Aleksandrov, M. P. Prange, S. Kerisit, M. E. Bowden, W. Cui, Z. Wang, N. R. Jaegers, T. R. Graham, M. Dembowski, H.-W. Wang, J. Liu, A. T. N'Diaye, M. Bleuel, D. F. R. Mildner, T. M. Orlando, G. A. Kimmel, J. A. La Verne, S. B. Clark and K. M. Rosso, ACS Appl. Nano Mater., 2018, 1, 7115-7128, doi: 10.1021/acsanm.8b01969.

[72] M. Trueba and S. P. Trasatti, Eur. J. Inorg. Chem., 2005, 2005, 3393-3403, doi: 10.1002/ejic.200500348.

[73] Q. Liu, A. Wang, X. Wang, P. Gao, X. Wang and T. Zhang, Microporous Mesoporous Mater, 2008, 111, 323-333, doi: 10.1016/j.micromeso.2007.08.007.

[74] R. A. Peterson, E. C. Buck, J. Chun, R. C. Daniel, D. L. Herting, E. S. Ilton, G. J. Lumetta and S. B. Clark, Environ. Sci. Technol., 2018, 52, 381-396, doi: 10.1021/acs.est.7b04077.

[75] P. Huestis, C. I. Pearce, X. Zhang, A. T. N'Diaye, K. M. Rosso and J. A. LaVerne, J. Nucl. Mater., 2018, 501, 224-233, doi: 10.1016/j.jnucmat.2018.01.043.

[76] L. M. Anovitz, X. Zhang, J. A. Soltis, E. Nakouzi, A. J. Krzysko, J. Chun, G. K. Schenter, T. R. Graham, K. M. Rosso, J. J. De Yoreo, A. G. Stack, M. Bleuel, C. Gagnon, D. F. R. Mildner, J. Ilavsky and I. Kuzmenko, Langmuir, 2018, 34, 15839-15853, doi: 10.1021/acs.langmuir.8b00865.

[77] M. Conroy, J. A. Soltis, R. S. Wittman, F. N. Smith, S. Chatterjee, X. Zhang, E. S. Ilton and E. C. Buck, Sci. Rep., 2017, 7, 13274, doi: 10.1038/s41598-017-13452-7.

[78] T. R. Graham, J. Z. Hu, X. Zhang, M. Dembowski, N. R. Jaegers, C. Wan, M. Bowden, A. S. Lipton, A. R. Felmy, S. B. Clark, K. M. Rosso and C. I. Pearce, Inorg. Chem., 2019, 58, 12385-12394, doi: 10.1021/acs.inorgchem.9b02000.

[79] W. Cui, X. Zhang, C. I. Pearce, Y. Chen, S. Zhang, W. Liu, M. H. Engelhard, L. Kovarik, M. Zong, H. Zhang, E. D. Walter, Z. Zhu, S. M. Heald, M. P. Prange, J. J. De Yoreo, S. Zheng, Y. Zhang, S. B. Clark, P. Li, Z. Wang and K. M. Rosso, Environ. Sci. Technol., 2019, 53, 11043-11055, doi: 10.1021/acs.est.9b02693.

[80] J. S. Lee, H. S. Kim, N.-K. Park, T. J. Lee and M. Kang, Chem. Eng. J., 2013, 230, 351-360, doi: 10.1016/j.cej.2013.06.099.

[81] S. R. Chauruka, A. Hassanpour, R. Brydson, K. J. Roberts, M. Ghadiri and H. Stitt, Chem. Eng. Sci., 2015, 134, 774-783, doi: 10.1016/j.ces.2015.06.004.

[82] A. Kocjan, P. J. McGuiness, M. R. Linarić and S. Kobe, J. Alloys Compd., 2008, 457, 144-149, doi: 10.1016/j.jallcom.2007.03.004.

[83] G. Antoniadis, K. M. Paraskevopoulos, D. Bikiaris and K. Chrissafis, Thermochim. Acta, 2009, 493, 68-75, doi: 10.1016/j.tca.2009.04.005. 
[84] R. M. R. Wellen and E. L. Canedo, Polym. Test., 2014, 40, 33-38, doi: 10.1016/j.polymertesting.2014.08.008.

[85] Z. Peng, L. X. Kong and S.-D. Li, Polymer, 2005, 46, 1949-1955, doi: 10.1016/j.polymer.2004.12.026.

[86] J.-W. Huang, Y. Chang Hung, Y.-L. Wen, C.-C. Kang and M.-Y. Yeh, J. Appl. Polym. Sci., 2009, 112, 3149-3156, doi:10.1002/app.29699.

[87] D. J. Y. S. Pagé and T. G. Gopakumar, Polym. J., 2006, 38, 920-929, doi: 10.1295/polymj.PJ2006020.

[88] Y.-1. Ma, G.-s. Hu, X.-l. Ren and B.-b. Wang, Mater. Sci. Eng. $\quad$ A, 2007, 460-461, 611-618, doi: .1016/j.msea.2007.01.133.

[89] P. Karmakar, A. K. Subudhi, K. Biswas and K. Annapurna, 2012, 540, 1-6, doi: 10.1016/j.tca.2012.04.008.

Thermochim. Acta, 2015, 610, 1-9, doi: 10.1016/j.tca.2015.04.019.

[90] H. R. Pouretedal and S. Loh Mousavi, J. Therm. Anal. Calorim., 2018, 132, 1307-1315, doi: 10.1007/s10973-0187028-y.

[91] .H. R. Pouretedal, M. Shahmoradi, A. Zareh and S. Sattar, J. Therm. Anal. Calorim., 2018, 135, 2975-2983, doi: 10.1007/s10973-018-7554-7.

[92] J. Xu, C. Zhu, X. Xie, C. Yan and Y. Wang, J. Therm. Anal. Calorim., 2020, 140, 2317-2324. doi: 10.1007/s10973019-09015-9.

[93] J. Ding, W. Peng, T. Luo and H. Yu, RSC Adv., 2017, 7, 6981-6987, doi: 10.1039/C6RA25120J.

[94] E. J. Choi, J.-C. Seo, H.-K. Bae and J. K. Lee, Eur. Polym. J., 2004, 40, 259-265, doi: 10.1016/j.eurpolymj.2003.08.009. [95] B.-D. Park and H.-W. Jeong, J. Ind. Eng. Chem., 2010, 16, 375-379, doi: 10.1016/j.jiec.2010.01.035.

[96] M. Fernández-Álvarez, F. Velasco, A. Bautista and J. Abenojar, J. Mater. Res. Technol., 2020, 9, 455-464, doi: 10.1016/j.jmrt.2019.10.073.

[97] J. S. Kashan, A. Jha, A. D. Thamir and J. T. Al-Haidary, J. King Saud. Univ. Eng. Sci., 2018, 30, 286-295, doi: 10.1016/j.jksues.2016.02.005.
[98] S. Vyazovkin, Cryst. Growth Des., 2018, 18, 6389-6392, doi: 10.1021/acs.cgd.8b01174.

[99] B. Janković, L. Kolar-Anić, I. Smičiklas, S. Dimović and D. Aranđelović, Thermochim. Acta, 2009, 495, 129-138, doi: 10.1016/j.tca.2009.06.016.

[100] M. Fatmi, F. Sahnoune, H. Belhouchet, T. Chihi, M. A. Ghebouli, B. Ghebouli, B. Barka and T. Rechidi, Chin. J. Phys., 2016, 54, 216-222, doi: 10.1016/j.cjph.2016.04.006.

[101] S. Vyazovkin, Macromol. Rapid Commun., 2002, 23, 771-775,doi: 10.1002/15213927(20020901)23:13<771::AIDMARC771>3.0.CO;2-G.

[102] R. L. Blaine and H. E. Kissinger, Thermochimica Acta, Author information

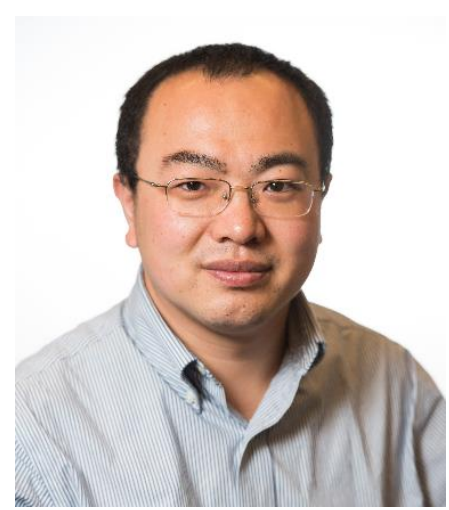

Dr. Xin Zhang received his doctoral degree in Chemical Engineering from Texas Tech University (U.S.A.) in 2014. Currently, he is a staff scientist in the Physical Science Division at Pacific Northwest National Laboratory (PNNL). His research focuses on materials synthesis, surface science, and crystal growth. He has authored over 100 publications in peer reviewed journals including Science, PNAS, Nat. Mater., Nat. Commun. and JACS. He has also authored 10 patents and several book chapters.

Publisher's Note: Engineered Science Publisher remains neutral with regard to jurisdictional claims in published maps and institutional affiliations. 